\title{
The Identification of Key Online Learning Dispositions of College Students Learning in A Blended Learning Course
}

\author{
Sharon Rolé
}

University of Malta

\section{ARTICLE INFO}

\section{Keywords:}

E-Learning

Resilience

Reciprocity

Responsibility

Resourcefulness

\begin{abstract}
This paper discusses part of a practitioner research case-study which I carried out with a class of thirty-seven college students learning chemistry in a blended learning context. The full two-year study involved a multimethod interpretivist approach using observations, unsolicited meetings, VLE tracking system, students' reflective journal, online informal discussions, questionnaires, focus groups and individual interviews. The study identified four key student online learning dispositions, i.e., the dispositions of resourcefulness, resilience, reciprocity and responsibility. These dispositions were identified as persona-related enablers for online learning and were found to be crucial for the students to develop a deep approach to learning. They were also instrumental for changes in the students as learners. These included changes in epistemological beliefs, study patterns, study habits and above all, changes in learner roles and learning identities. Notable changes occurred in a group of learners who were initially reluctant to learn from the online environment. This study showed that student learning dispositions may be transferred from one context to another. This includes a transfer of learning dispositions from the online environment to the face-to-face traditional classroom setting. Several educators argue that learning dispositions should be included as educational goals in educational curricula and should serve as practical strategies in creating learning environments. Learning activities should provide students with opportunities to develop and cultivate desirable dispositions for learning.
\end{abstract}

\section{Introduction}

This paper discusses the identification and exploration of online learning dispositions of thirtyseven college students who participated in a blended learning chemistry course. The study is part of a larger research work which was an inquiry into the online learning experiences of the students (Rolé, 2014).The key dispositions of resourcefulness, resilience, reciprocity and responsibility were classified as persona-related enablers amongst several factors which were found to affect learning.

Learning dispositions are visualised as habits of mind and tendencies of students to respond to situations in a characteristic kind of way (Katz, 1988). Dweck (2006) noted that beliefs result in dispositions and these are indicated by actions. Deaken et al (2008) argued that learning dispositions reflect the learning identity of a learner, and at the same time they enhance learning and result in further learning. Several educators, being conscious of the importance of learning dispositions, provided their own lists. Examples include Claxton and Carr (2004), in childhood settings, listed resilience, playfulness and reciprocity and Bernard et al (2004), in online settings, listed a readiness to interact, to give timely feedback and to support other students.

\footnotetext{
* Corresponding Author E-Mail Address: sharon.role@um.edu.mt 
The designed collaborative blended learning course, which supported this case-study research, proved to be instrumental for the development of desirable online learning dispositions in students. Four dispositional domains were identified and explored.

\section{Methodology - Practitioner Research}

As a practitioner I designed, implemented and conducted a blended learning course with students who were accustomed to traditional face-to-face learning based on an individualistic and ritualized approach (Boaler \& Greeno, 2000). The course was designed on the supplemental model where the online work complemented the learning in the face-to-face class. Most online work was based on a socio-constructive approach to learning and included the use of wikis, discussion fora, glossary and lab simulation tasks, which were accessed from the virtual learning environment (VLE) Moodle 4.1. Face-to-face learning involved lectures and discussions in the classroom. The case-study data generation methods were integrated within the course.

As a researcher, I designed and implemented a multi-method interpretivistic research inquiry to explore the students' response to the innovative learning strategy. An interpretive phenomenological approach (Smith et al, 2009) framed the study. The main study (Table 1) was carried out during 34 weeks in the academic year 2007-2008, and this was preceded by a four-month exploratory study in the previous year $2006-2007$, with a different cohort of college students.

\subsection{The case-study design}

Table 1 indicates the data generating methods which were used and the period when the research method was employed. A zooming-in approach (Nisbet \& Watt, 1984) was used to allow (1) an insight of online collaborative learning as experienced by all the students, and (2) a focus on a resilient group of twelve students.

Table 1.

Data generating methods and the time frame for data collection

\begin{tabular}{|c|c|c|}
\hline Week & Tool/ Research method & Data \\
\hline 1 & Questionnaire 1: student profile questionnaire & Students' familiarity with technology \\
\hline $1-28$ & Unsolicited face-to-face chats with students & Students'thoughts on course activities \\
\hline $1-32$ & Researcher's journal & Observation, reflections and development of ideas. \\
\hline $1-32$ & Virtual Learning Environment tracking system & Students' access and engagement in the VLE. \\
\hline $1-2$ & Informal online fora & $\begin{array}{l}\text { Students' perceptions of online learning and } \\
\text { collaborative learning. Use of Ice-breaker } \\
\text { activities. }\end{array}$ \\
\hline 5 & Student's reflective journal & Reflections on some online activities. \\
\hline 7 & Questionnaire 2: early stages questionnaire & Students' developed attitude towards course. \\
\hline 8 & Two ad-hoc group interviews & Purposeful selection of non-participating students \\
\hline 16 & Questionnaire 3: Middle Stages questionnaire & Functioning of groups and the students ${ }^{6}$ roles \\
\hline $23-24$ & Two focus group meetings & Students' perceptions and experiences. \\
\hline $28-34$ & $\begin{array}{l}23 \text { Individual interviews; } 12 \text { in-depth } \\
\text { interviews }\end{array}$ & Students' perceptions and experiences. \\
\hline
\end{tabular}

The generated data was stored, coded, categorised several times, reduced and analysed using the qualitative analysis software Nvivo 8. The intense coding and reiterated categorisations of the data gave me a deep understanding of the students' experiences of online participation. The findings from the final individual and in-depth interviews (weeks 28-34) at the end of the seven-month course were treated as primary data. This data was triangulated with the other generated data (weeks 1-24) (see Table 1). 


\section{Findings and Discussion}

The findings and discussion in the sections (3.1.1) and (3.1.2) provide the context to those in section (3.2), which concerns learning dispositions. In this work, I adopted the practice of using pseudonyms and not the students' real names.

\subsubsection{Behaviour patterns}

Table 2.

Behaviour groups and the students in each group (Rolé, 2014)

\begin{tabular}{lllcl}
\hline Behaviour group & Meaning of term & Course Participation & Number of Students & $\%$ \\
\hline Marcato & emphatic & Full & 1 & 3 \\
\hline Moderato & moderate speed & Part & 9 & 24 \\
\hline Crescendo & becomes louder & Increases & 12 & 32 \\
\hline Diminuendo & becomes softer & Decreases & 4 & 11 \\
\hline Staccato & detached & Episodic & 7 & 19 \\
\hline Ritenuto & held back & None & 4 & 11 \\
\hline
\end{tabular}

Teenagers are said to be digitally literate (Prensky, 2001), with a desire to be connected to each other and to the Internet (Oblinger \& Oblinger, 2005). The learners' profile questionnaire (see Table 1) revealed that $84 \%(n=31)$ of the class were familiar with and liked technology. Nevertheless, a diversity in online student behaviour patterns emerged. These patterns rendered six student behaviour groups, which for easy reference, were likened to terms selected from music dynamics (Table 2). Table 2 also gives the number and percentage of students with a particular type of behaviour pattern.

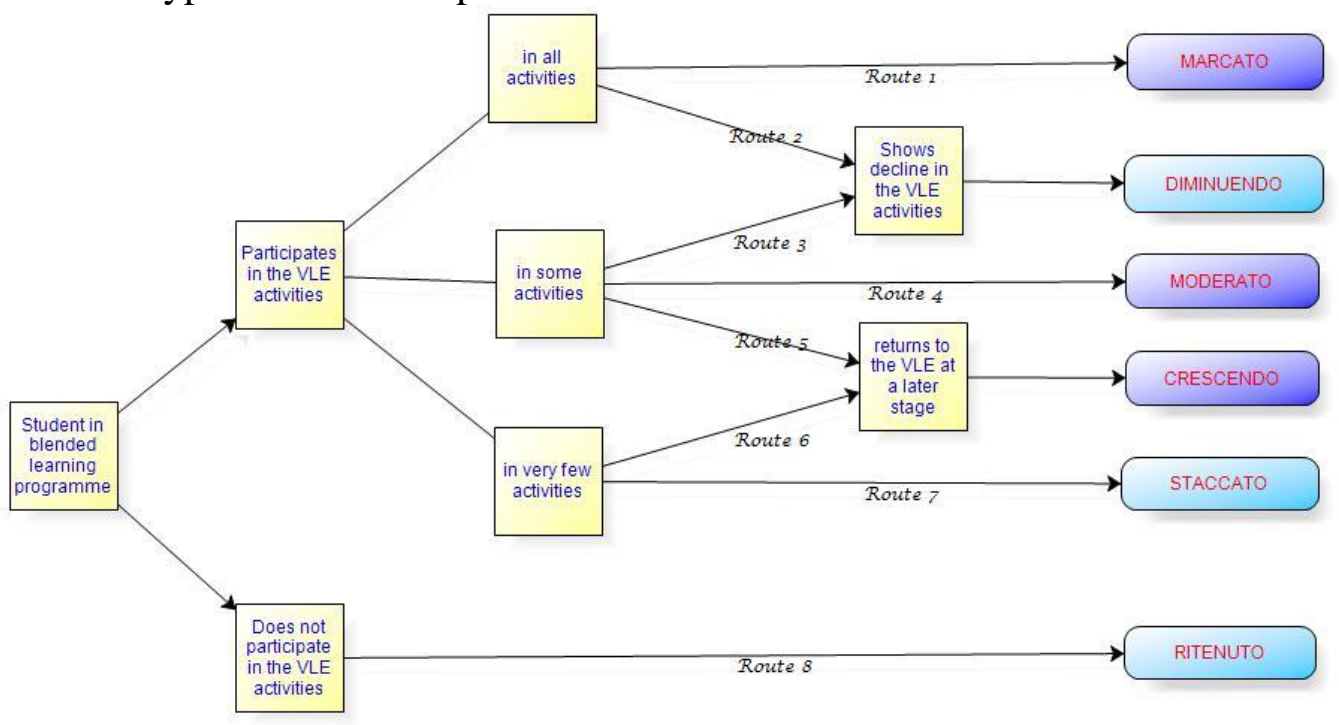

Figure 1. The online behaviour patterns (Rolé, 2014)

Figure 1 illustrates the online journeys of the Marcato, Moderato, Crescendo, Diminuendo, Staccato and Ritenuto students. The enthusiastic Marcato student (Route 1) participated in all activities. The Crescendo students (Route 5) were the resilient students who eventually became full contributors. The Moderato students (Route 4) participated in small group work but not in whole class discussions. Data analysis revealed that $59.46 \%$ of the class $(n=22)$ formed an active online learning community composed of the Marcato, Moderato and Crescendo students. Analysis also showed that successful online collaborative learners met the following three challenges: (1) the acceptance of online learning as a learning method, (2) the ability to use the computer, Internet and VLE tools and (3) contribution to online collaborative activities. 


\subsubsection{The factors which influenced online behaviours}

Table 3.

A framework of the factors affecting online participation (Role, 2014)

Inhibitors and Enhancers

\begin{tabular}{lll}
\hline 1 & Situational & Time-management, online learning/VLE issues, experiential and out-of-class opportunities \\
2 & Infrastructural & Institutional issues and outside-college settings \\
3 & Persona-related & Epistemological beliefs, personal states, computer use skills and learning dispositions \\
\hline
\end{tabular}

In this study, I extended Garland's (1993) framework of inhibitors as a model to suit my data of inhibitors and enablers. The factors were categorised in three main themes - situational, infrastructural and persona-related (see Table 3).

Situational factors were due to the personal choices (Stanford-Bowers, 2008) and unless the students themselves were prepared to change their lifestyle, they could not be able to meet the challenges. This was the case with the Diminuendo, Staccato and the Ritenuto students. In contrast, the Crescendo students, were resilient and able to overcome their situational problems. The infrastructural factors involved institutional and home limitations to the access of computers and the Internet. Despite the fact that all the students in the class had computer and Internet access at home, some students had connectivity and use issues.

The persona-related factors included (1) the students' epistemological beliefs regarding selfdirected learning and collaborative learning, (2) personal states such as shyness, (3) online reflective and writing skills and (4) learning dispositions which are the findings described in the next section 3.2 .

\subsection{Learning dispositions as enablers for online collaborative learning}

Learning dispositions are described by Claxton and Carr (2004) as the readiness and the willingness to learn. Katz (1988) argued that it is useless for students to be taught skills, if the disposition to use such skills is not present e.g., a student may be taught how to read, but the intense practice may make the student dislike reading. Data analysis in this study, revealed the learning dispositions of resourcefulness, resilience, reciprocity and responsibility as the dispositional pillars of online collaborative participation. The emerging data indicated that the Marcato, Crescendo and Moderato students demonstrated the dispositions of resourcefulness, reciprocity and responsibility. In addition, the Crescendo students gave evidence of the disposition of resilience. The Staccato and Ritenuto students lacked these positive dispositions and were unable to participate in the VLE. The Diminuendo students gave evidence of some of the dispositions at the beginning of the course, but lacked the disposition of resilience and failed to persist in further participation.

\subsubsection{Disposition of Resourcefulness}

The disposition of resourcefulness focuses on the cognitive aspects of learning. This disposition was indicated by (1) a curiosity about online learning and an academic curiosity, (2) a confidence in the new learning design, in the teacher and in themself as a learner, and (3) a flexibility in the appropriate use of different resources.

Curiosity, in this case, a sub-disposition of resourcefulness is indicated by asking questions and exploration. It is the motivational process for learning, implying that students need to be curious to learn (Goleman, 1996). In the first two weeks of the blended course, twenty-seven students $(80 \%)$ had self-enrolled in the VLE. In the case of the Marcato and Moderato students and later, the Crescendo students, the initial curiosity to access the VLE led to academic curiosity which was characterised by exploration, and interest to solve problems in the discussion fora and wikis. In this zone of curiosity (Day, 1982), the online participants became cognitively engaged in research and problem-solving activities. 
'When I have a problem I would want to solve it ....... Anthony and I could not agree on an issue which we were discussing online. I was not sure myself, but I was not convinced of what he was saying. It took us some days, but finally we worked it out, ' Kate (Crescendo), in-depth interviews, May 2008.

Curiosity was also instrumental for at least six Crescendo students who observed other students solving chemistry problems. They were able to fill the gap between what they do not know and what they must know to resolve their cognitive conflicts. The Ritenuto, Staccato and eventually the Diminuendo students were below the optimal level of curiosity and lacked the motivation to explore resources, both in terms of research and also to learn with and from peers. The online behaviour of these students was characterised by avoidance, defensiveness, and disinterest.

The sub-disposition of having confidence was apparent in resourceful students as confidence in (1) the innovative learning setting, (2) their abilities and their work, and (3) other students engaged in collaborative work. The enthusiastic Marcato student expressed a confidence in the learning design, his ability to do research, understanding chemistry, explaining to other students and assessing his own learning.

'Another way to learn. I accepted it like it was a lesson, another resource, I was looking forward to use Moodle. I see what problems other students have. I was not always able to solve problems, but I used to do some research, so that first I understand the concepts well and then I help the others; and I could tell how well I knew the topic myself,' Anthony (Marcato), individual interviews, May 2008.

Resourceful students showed a mutual confidence in each other as they learnt together and from each other. This confidence was also demonstrated in the small groups:

'We checked and discussed each other's work in the wiki and put in comments until we agreed on everything, ' Kelly, (Moderato) individual interviews, May 2008

The students were aware that having confidence in each other was a crucial issue in collaborative work. In the first collaborative task, some students were disappointed with the presence of non-contributors in the groups, and requested to have student self-selected groups. They argued that teaming up with class-mates that one has confidence in, would be to the group's advantage.

Flexibility, a sub-disposition of resourcefulness, is defined by Collis and Moonen (2001) as learner choice in a learning experience in terms of resources and activities. Flexibility was indicated when students learnt from alternative or additional methods of learning. Additional learning resources were either suggested by the teacher or discovered by the students themselves.

Some students were not disposed to look at alternative learning resources. The Staccato students and initially some Crescendo students, who had considered online work as unnecessary or optional were not flexible. One Crescendo student considered using the VLE, only when he was told that the work was part of the homework. Doreen, another Crescendo student was initially in the course, reluctant to become an active learner.

'I preferred to find the explanation already there - in the notes. I would read it and understand it.....trying to solve problems and researching was tedious,' Doreen (Crescendo), Focus group 2, April 2008.

Students who did not grasp opportunities to further their learning and who relied solely on the teacher's notes were not flexible. The Staccato, the Ritenuto and the Diminuendo students resisted the use of innovative methods of learning. Students with the disposition of resourcefulness e.g., the Marcato, at times the Moderato and eventually the Crescendo students, became self-directed learners demonstrating independence, self-management, and a desire for learning. The students who lacked this disposition of resourcefulness, namely the Staccato and the Ritenuto students, did not meet the first challenge i.e., the acceptance of online learning as a learning method and hence met none of the other challenges. 


\subsubsection{Disposition of resilience}

This disposition focuses on the emotional aspects of learning. It is conceptually described by Claxton and Carr (2004) as an inclination to take on challenges when outcomes are uncertain, to persist despite temporary confusion or frustration, to recover from setbacks, and to rededicate oneself. The reluctance to use the VLE for collaborative learning was due to several factors, but the most common inhibitors were (1) epistemological beliefs favouring a teacherreliant and an individualistic learning approach, (2) personal states of shyness and of low selfesteem in using computers and contributing to the whole-class discussions, (3) online engagement skills regarding writing and reflecting, and (4) a will to keep Internet use for leisure and not academic work. Table 4 shows how Jodie, a Crescendo student, was unable to meet the listed (numbered) challenges due to uncertainties but being resilient, the student persisted and after two months, she participated fully in the VLE activities.

Table 4.

The inhibiting factors affecting two Crescendo students

\begin{tabular}{|c|c|c|c|}
\hline Student & Challenge & Inhibitors/uncertainties/frustrations & $\begin{array}{l}\text { Recovery/rededication and time } \\
\text { period for change }\end{array}$ \\
\hline Jodie & $\begin{array}{l}1 \\
2 \\
2 \\
3 \\
2 \\
3\end{array}$ & $\begin{array}{l}\text { Uncertainty issues - VLE for learning } \\
\text { Writing chemistry and mathematical text in the VLE } \\
\text { Reflecting and writing using the keyboard } \\
\text { Lack of self-confidence - discussing and posting } \\
\text { Internet for leisure } \\
\text { Shyness }\end{array}$ & $\begin{array}{l}\text { After two months, Jodie realised } \\
\text { that she was falling behind in } \\
\text { chemistry and that online } \\
\text { learning would meet her learning } \\
\text { needs. }\end{array}$ \\
\hline
\end{tabular}

This learning disposition enabled the Crescendo students ( $n=12,32 \%$ of class) to persevere through their uncertainties and frustrations. The disposition of resilience was exhibited by the students in terms of persisting (1) as online collaborative learners and (2) in solving chemistry problems. In contrast, the Diminuendo students $(n=4,11 \%)$ who only participated in first few months clearly lacked this disposition.

\subsubsection{Disposition of Reciprocity}

A crucial disposition for online collaborative learning is doubtlessly the learning disposition of reciprocity, which focuses on the socio-constructive dimension of learning. Reciprocity in this research context denotes an interacting relationship between learners, where an interchange of ideas in response to questioning and problem-solving activities took place in asynchronous communication in the discussion fora and in the wikis. It resulted in the creation of learner generated knowledge. This disposition was crucial for learners participating at the knowledge building level to co-construct their knowledge through participation (Gunawardena et al., 1997). Students, who lacked this disposition, were unable to cope with the third challenge which was to discuss and contribute to the generation of knowledge in the online environment. Claxton and Carr (2004) listed the following indicators: (1) to engage in joint learning tasks, (2) to express uncertainties, (3) to be questioning, (4) to take a variety of roles and (5) to take others' purposes and perspectives into account.

The learning disposition of reciprocity gave rise to learner interactions and created social, cognitive, and teaching presences (Garrison et al., 2000). As the Marcato, Moderato and Crescendo students reciprocated and became engaged in joint online learning tasks in wholeclass discussions in fora and in small group work in wikis, they took on the roles of helpseekers and knowledge-mediators. The following comment illustrates how a Moderato student visualised learning in the online community. 
'.... (In Moodle) you always continue learning; you see everyone, it is like a process, adding to the knowledge which one already has...,' Rita (Moderato), individual interviews, May 2008.

The VLE provided a medium which, allowed the students to observe each other learning. The cognitive and teaching presences were maintained by learners in the discussions in the fora and in the wikis. This was different to the face-to-face class scenario, where each student was conscious only of his learning through learner-teacher and learner-subject content interactions. In the online setting, learners could compare their understanding to that of other learners. This created an environment where learners clarified and reinforced their understanding of concepts together. Cognitive presence was created as students constructed and confirmed meaning through reflection and discourse (Kanuka \& Garrison, 2004). In this process they listened to each other, developed as inquirers, explored solutions and discussed together and with the teacher.

'I do my research and be the first to put my answers in the wiki. My friends add more sections. Then we discuss and leave the good parts as an answer. There were times they did not know how to answer. I will then explain the work,' Anthony (Marcato), individual interviews, May 2008.

The above comment reveals a scenario in small group-work, where the Marcato student helps other students who were in the zone of proximal development (Vygotsky, 1978). Teaching presence was also created as the online participant students facilitated discussions, taught each other and learnt from each other while they discussed and shared problems in fora and in wikis. Social presence, defined as the ability of learners to project themselves socially and emotionally in a community of inquiry (Garrison et al., 2000) is crucial to maintain both cognitive and teaching presence (Lehman \& Conceicao, 2010). The following comment illustrates how the reciprocating behaviour of the students changed the virtual space into a safe and comfortable place for meetings outside the College walls.

'Normally, one does not go around asking others, - I cannot understand this concept bla bla bla, but in the VLE, since everyone is there discussing and asking, you feel, I am not on my own, it is comforting, I can ask in here, this is what this is for, ' Rita (Moderato), individual interviews, May 2008.

\subsubsection{Disposition of Responsibility}

The disposition to take responsibility for learning is fundamental, and it re-enforces and is reenforced by the presence of the dispositions of resourcefulness, resilience and reciprocity. In traditional teacher-centred learning, the students rely for their learning mainly on the sense of responsibility of the teacher. In this course, the knowledge-mediators and help-seekers interacted together and shouldered the responsibility for their learning and that of their peers; they became self-directed and collaborative learners and also partners with the teacher in the learning process.

Anderson and Prawat (1983) stated that a sense of responsibility is made visible by behaviour, and is affected by invisible components such as beliefs and attitudes. In this section, I describe the behaviours of the Marcato, Crescendo and Moderato students, and provide evidence that a sense of responsibility was needed for the building of the online learning community. The learning disposition of responsibility focusses on the moral aspect of learning and is discussed in two parts: (1) Disposition of taking the responsibility to manage one's learning and (2) Disposition of taking the responsibility for the learning of other students.

\subsubsection{The disposition of taking the responsibility to manage one 's learning}

The learning disposition of taking the responsibility to manage one's learning was indicated when students managed their own learning and became self-directed learners. Self-directed 
learners are able to assess their needs, secure learning resources, implement learning activities and evaluate learning (Guglielmino \& Guglielmino, 2003); they take control of the learning process by employing self-regulatory and resource management strategies (Pintrich \& De Groot, 1990).

Students were traditionally accustomed to rely on the teacher's sense of responsibility for their learning by learning what they thought the teacher wanted them to learn. Online learning gave rise to a shift in learning responsibility from the teacher to the learner and it changed the way students studied. The students gained control over (1) what they needed to learn (2) how to learn it and (3) the time needed for learning.

The Marcato student was a resourceful student, who had confidence in his abilities to research and to understand concepts, who was ready to explain to other students and, who at the same time assessed his own learning. The Crescendo students showed a disposition to take responsibility for their learning, when they took the initiative to work without the teacher's intervention, tackled more work and became less teacher reliant.

Some learners developed self-regulatory strategies (Pintrich \& De Groot, 1990) to master the subject content. Similar to the Marcato student, they eventually became capable of managing their own learning by assessing their learning, determining what was relevant to their needs, and choosing what and how to study.

Doreen, the Crescendo student, who had said that researching and problem-solving were tedious developed the disposition to take responsibility for her learning by becoming conscious of her learning needs, developing an interest in doing research and showing a determination to achieve mastery of the content.

'Moodle changed the way I studied. Through Moodle I developed an interest in

looking up things that I did not understand. If I do not solve the problem, I discuss

it in the forum, 'Doreen (Crescendo), in-depth interviews, May 2008.

This disposition was indicated in different ways; students developed different strategies such as observing other students, persisting to solve problems and to compare their understanding with that of other students. Paula observed other students and developed strategies to imitate them. She used help-seeking strategies such as learning from others and discussing with them (Pintrich \& De Groot, 1990).

\section{'...I watched the others work hard and participate, especially Kate and Anthony. I used to tell myself, why should I not do so as well..." Paula, (Crescendo), in-depth interviews, May 2008}

Several online learners took ownership of their learning process and from non-collaborators in the online medium and in the face-to-face class, they became self-directed and collaborative learners. This section showed that the indicators for a disposition to take responsibility for one's learning are the development of (1) self-regulatory strategies such as identifying needs in the learning process, assessing and evaluating learning, and (2) resource management strategies which include effective study skills.

\subsubsection{The disposition of taking responsibility for the learning of other students}

In whole-class discussions and in small group-work, the learners established a sense of community and ensured a flow of information, social support, commitment to group goals, and satisfaction with the learning experience (Rovai et al 2004). Abedin et al (2010) remarked that learners who have formed a community, feel a sense of belonging, of connectedness, of cohesion, of community spirit, of membership and of influence. These authors added that learners with a sense of community respect, trust, rely on each other, share emotional connection and are aware of each other's activities, perspectives and needs. Palloff and Pratt (2003) considered a disposition to take on the responsibility for community formation as an essential learner characteristic for online learning and added that the individual learning 
process of the virtual student is dependent on the participation and commitment of the other students in the group. This section provides evidence of students who developed the disposition to take responsibility for the learning of other students in both small group-work and wholeclass discussions.

The following comments indicate the disposition of taking responsibility for the learning of other students in small group work:

'I feel greatly responsible for the others to learn. If it is just me, I may postpone doing the work, but in our group I do it. I know the others depend on me. I'd be very concerned. You do the work willingly for yourself and for the team,' Doreen (Crescendo), in-depth interviews, May 2008.

The Marcato student, two Crescendo students and one Diminuendo student who were the active participants in the first term were conscious of the learning needs of other students. With a sense of responsibility, they researched their work and initiated whole-class discussions. In the week before each chemistry face-to-face class test, the Marcato student made himself available online on all evenings to discuss problems posted by other students. Following this, he also became a constant support to students in chemistry and in another subject and led face-to-face discussions in the library and in the classrooms at the College.

As evidenced in the following comment, the active learners in whole-class discussions created a community spirit and a sense of belonging amongst the participating students:

'Moodle bonded the class from the very start. It kept the class together throughout the year. We all knew we could ask in Moodle.... Moodle helped us to get to know each other and gave us the chance to help each other,' Sylvia (Crescendo), indepth interviews, May 2008.

The disposition of taking responsibility for the learning of other students was expressed in terms of (1) keeping the group collaborating in small group-work, and (2) helping students understand chemistry content in both small group-work and in whole-class discussions. This study showed that the indicators for the disposition of taking responsibility for the learning of other students are a willingness to (1) take roles and be caring, open, honest, reliable (2) visit frequently the online environment to respond to posts with problems/issues (3) research problems and issues raised by other students (4) actively take part in discussions (5) ensure that the issue/problem has been solved and understood by all concerned, and (6) convey a spirit of collaboration and connectedness.

\section{Conclusion}

This study provided evidence that students took up opportunities to develop the online learning dispositions, which were instrumental for changes in the students as learners. These changes included:

- a change in the students' epistemological beliefs, becoming less reliant on the teacher for their learning and aware of the benefits of collaborative learning;

- a change in learner identity- a shift in roles from non-collaborators to help-seekers and some to knowledge mediators; becoming self-directed learners and collaborative learners, gaining self-confidence and developing agency and empowerment;

- a change in study patterns and study habits.

- a change in community wellbeing - development of a sense of belonging and community spirit which was created in the online community and was also transferred to the face-to-face class.

The online setting afforded a medium which allowed the shift and practice of roles. This research provided evidence, that the new socio-constructive learning approaches which were developed in the online setting induced pedagogical changes in the face-to-face environments 
as students started practicing help-seeker and knowledge mediator roles in the face-to-face class and library as well.

As Claxton and Carr (2004) and Dweck (2006)) proposed, the emphasis in teaching should be made at developing and cultivating positive learning dispositions in students in addition to teaching subject content. Students, in turn need to be in learning environments which allow them to practice learning dispositions and where they can acknowledge and appreciate the learning dispositions.

\section{Acknowledgment}

This study is part of a much larger research undertaken for my doctorate thesis (see Role 2014 below). I would like to thank Professor Gordon Joyes who was my supervisor for his invaluable guidance and advice during my PhD journey. School of Education, University of Nottingham, March 2014.

\section{References}

Abedin, B., Daneshgar, F. and D'Ambra, J. (2010). Underlying factors of sense of community in asynchronous computer supported collaborative learning environments. MERLOT Journal of Online Learning and Teaching, 6(3), pp.585-596. http://jolt.merlot.orgvol6no3/ abedin_0910.pdf

Anderson, L. M. and Prawat, R. S.(1983). Responsibility in the classroom: a synthesis of research. Educational Leadership, pp.62-66. http://www.ascd.org/ASCD/pdf/journals/ed_ lead/el_198304_anderson.pdf

Bernard, R. M., Abrami. P.C., Loy, Y.,Borokhovski, E., Wade, A., Wozney, L., Wallet, P.A., Fiset, M. and Huang, B. (2004). How does distance education compare with classroom instruction?: a met-analysis of the empirical literature. Review of Educational Research, vol.74, pp.379-439.

Boaler, J. and Greeno, J. G. (2000). Identity, agency and knowing in Mathematics Worlds. In: J. Boaler, ed. Mutiple perspectives on mathematics teaching and learning, Westport: Ablex, pp.171-200.

Claxton, G. and Carr, M. (2004). A framework for teaching learning: the dynamics of disposition. Early Years, vol.24, pp.87-97.

Collis, B. and Moonen, J. (2001). Flexible learning in a digital world: experiences and expectations,London: Kogan Page.

Day, H. I. (1982). Curiosity and the interested explorer. NSPI Journal, vol.21, pp.19-22.

Deaken Crick, R. and Yu, G. (2008). Assessing learning dispositions:is the effective lifelong learning inventory valid and reliable as a measurement tool? Educational Research, vol.50, pp.387-402.

Dweck, C. (2006). Mindset: the new psychology of success, New York: Random House.

Garland, M. R. (1993). Student perceptions of the situational, institutional, dispositional and epistemological barriers to persisitence. Distance Education, vol.14, pp.181-198.

Garrison, D. R., Anderson,T. and Archer,W. (2000). Critical Enquiry in a Text-based Environment Computer Conferencing in Higher Education. The Internet and Higher Education, vol.2, pp.1-19.

Goleman, D. (1996). Emotional Intelligence, New York: Bantam Doubleday Dell. 
Guglielmino, L. M. and Guglielmino, P. J. (2003). Identifying learners who are ready for elearning and supporting their success. In: G.M.Piskurich, ed. Preparing learners for elearning, San Francisco CA: Pfeiffer, pp.19-34.

Gunawardena, C. N., Lowe, C. A. and Anderson, T. (1997). Analysis of a global online debate and the development of an interaction analysis model for examining social construction of knowledge in computer conferencing. Journal of Educational Computing Research, vol. 17, pp.397-431.

Kanuka, H. and Garrison, D. R. (2004). Cognitive presence in online learning. Journal of Computing in Higher Education, vol.15, pp. 21-39.

Katz, L. G. (1988). What should young children be doing? American Educator, vol.12, pp.2833.

Lehman, R. M. and Conceicao, S. C. O. (2010). Creating a sense of presence in online teaching- How to "be there" for distance learners, San Francisco CA: Jossey-Bass.

Nisbet, J. and Watt, J. (1984). Case Study. In J.Bell, T.Bush, A.Fox, J.Goodey and S.Goulding, eds. Conducting small scale investigations in Educational Management, London: Harper and Row, pp.79-92.

Oblinger, D. G. and Oblinger, J. L. eds. (2005). Educating the Net generation. http://www.educause.edu/ir/library/pdf/pub7101.pdf

Palloff, R.M. and Pratt, K. (2003). The virtual student: a profile and guide to working with online learners, San Francisco CA: Jossey-Bass.

Pintrich, P. R. and De Groot, E. V. (1990). Motivational and self-regulated learning components of classroom academic performance. Journal of Educational Psychology, vol.82, pp. 33-40.

Prensky, B. M. (2001). Digital natives, digital immigrants, On Horizon, vol.9, pp.1-6.

Rolé, S. (2014). An inquiry into factors affecting the online learning experiences of A-level chemistry students studying in a blended learning course in a college in Malta and the impact of these experiences on learning identity. Doctoral thesis. The University of Nottingham. http://eprints.nottingham.ac.uk/14511/

Rovai, A. P.,Wightinga, M. J., and Lucking, R. (2004). The classroom and school community inventory: development, refinement, and validation of a self-report measure for educational research. Internet and Higher Education, vol.7, pp.263-280.

Smith, J. A., Flowers, P. and Larkin, M. (2009). Interpretive Phenomenological Analysis: theory, Method and Research, London: Sage.

Stanford-Bowers, D. E. (2008). Persistence in online classes: a study of perceptions among community college stakeholders. MERLOT Journal of Online Learning and Teaching, vol.4, pp.37-50.

Vygotsky, L. S. (1978) L. S. Vygotsky: Mind in Society: the development of higher psychological processes. Edited by M. Cole, V. John-Steiner, S. Scribner and E. Souberman, translated by A.R.Luria, M. Lopez Morillas, M. Cole and J. Wertsch. London: Harvard University Press. 